\title{
Presença de Campylobacter spp. em macacos-de-cheiro (Saimiri spp.) assintomáticos cativos e sua correlação com as condições de manejo
}

\author{
[Campylobacter spp. in asymptomatic captive squirrel monkeys (Saimiri spp.) \\ and its correlation with the handling conditions] \\ M.C.R. Andrade, D.A. Lopes, S.C.O. Gabeira, W.T.C. Esteves, M.C.B. Vilardo, \\ J.D.S. Thomé, A.L. Lauria-Filgueiras \\ Fundação Oswaldo Cruz \\ Av. Brasil, 4365 \\ 21040-900 - Rio de Janeiro, RJ
}

\begin{abstract}
RESUMO
Avaliou-se a circulação de Campylobacter spp. em uma criação de primatas neotropicais macacos-decheiro (Saimiri spp.), clinicamente saudáveis, utilizados em investigações biomédicas. A análise foi feita no decorrer de sete anos não consecutivos, de 1995 a 1999, 2002 e 2003. Os resultados revelaram um maior índice de positividade no ano de 1996, em contraste com a ausência do agente em 2003. Os dados sugerem que as alterações realizadas no manejo animal, ao longo deste estudo, foram eficazes para a eliminação do Campylobacter spp. na criação de macacos-de-cheiro, levando os animais a uma melhor qualidade de vida e, consequentemente, obtendo-se um melhor produto para fins de pesquisas.
\end{abstract}

Palavras-chave: primatas neotropicais, campilobacteriose, manejo animal

\begin{abstract}
The circulation of Campylobacter spp. in a breeding colony of clinically healthy neotropical primates squirrel monkeys (Saimiri spp.) used in biomedical investigation was evaluated. Analyses were undertaken during seven non-consecutive years: 1995 to 1999, 2002 and 2003. Results revealed a higher rate of positivity in 1996, in contrast to the absence of the agent in 2003. The data suggest that the changes made in the animal management during this study were effective for the Campylobacter spp. elimination of the squirrel monkeys breeding colony, leading to a better quality of life and, hence, resulting in a better animal for research.
\end{abstract}

Keywords: neotropical primates, campylobacteriosis, animal handling

\section{INTRODUÇÃO}

Doenças bacterianas, como a campilobacteriose, atuam como importantes causas de morbidade e até mortalidade, afetando tanto os primatas neotropicais de vida livre quanto os cativos. Um outro ponto relevante desta infecção é o seu aspecto zoonótico, sendo extremamente necessário que os seres humanos que manejam os primatas neotropicais adotem determinadas precauções e que sigam os devidos procedimentos operacionais padrões, evitando, assim, situações indesejáveis de contaminações diretas ou indiretas (Dubois, 1996; Diniz, 1997; Montali e Bush, 1999). Campylobacter spp. é uma bactéria comensal do sistema digestivo, pode apresentar-se de forma enteropatogênica e auto-limitante, amplamente distribuída pelo mundo, causando quadros diarreicos em humanos e em primatas não-humanos de laboratório, nos quais o quadro infeccioso se estabelece pela rota orofecal (Bennett et al., 1995).

Ainda não está esclarecida a importância etiológica dessa bactéria em primatas de 
laboratório (Russel et al., 1988). De acordo com Sá et al. (2001), o isolamento de Campylobacter spp. a partir das fezes de animais com diarreia ou assintomáticos é amplamente relatado, tanto em animais domésticos como silvestres, incluindo os primatas neotropicais. Um estudo retrospectivo de 20 anos responsabiliza as bactérias enteropatogênicas, dentre elas Campylobacter spp., por $7 \%$ dos problemas de saúde de uma colônia de Callithrix jacchus (Diniz e Costa, 1995). Uma análise de cinco anos de necropsias realizadas em primatas neotropicais revelou a presença de diversas bactérias enteropatogênicas, incluindo Campylobacter jejuni (Gozalo e Montoya, 1990; 1992).

Campylobacter jejuni também já foi isolado em mico-leões-dourados (Leontopithecus rosalia), estando associado com doenças intestinais nas colônias de Calitriquídeos (Montali e Bush, 1999). Gozalo et al. (1991) verificaram maior prevalência do organismo em amostras fecais de Saguinus spp. recém-capturados do seu habitat do que em calitriquídeos mantidos em cativeiro por mais de um ano, não havendo correlação entre os episódios de diarreia e os animais infectados.

O envolvimento de Campylobacter spp. no desenvolvimento dos processos zoonóticos e enteropatogênicos tem sido amplamente discutido. Contudo, são extremamente escassos os relatos científicos que correlacionam a presença desse microrganismo com primatas neotropicais. Visto que o manejo animal adotado em uma criação influencia diretamente na presença do referido patógeno (Evans et al., 2003), avaliou-se a dinâmica comportamental de Campylobacter spp. em um criadouro de macacos-de-cheiro (Saimiri spp.), em relação às alterações nutricionais, sanitárias e estruturais de recinto, ao longo dos anos de 1995 a 1999, 2002 e 2003.

\section{MATERIAL E MÉTODOS}

Foram analisadas 433 amostras fecais de macacos-de-cheiro (Saimiri spp.), destinados à pesquisa biomédica, pertencentes ao criadouro científico do Departamento de Primatologia do Centro de Criação de Animais de Laboratório (Cecal) da Fundação Oswaldo Cruz (Fiocruz) nos anos de 1995 a 1999, 2002 e 2003. Os animais foram separados nas faixas etárias: infantil (de 0 a 12 meses), juvenil (de 13 a 36 meses), subadulto (de 37 a 60 meses) e adulto (acima de 60 meses). A Tab. 1 mostra o número de animais estudados de acordo com o sexo e as faixas etárias.

Tabela 1. Número de macacos-de-cheiro estudados de acordo com sexo e faixa etária

\begin{tabular}{cccccc}
\hline Ano & Infantil $(\mathrm{m} / \mathrm{f})$ & Juvenil $(\mathrm{m} / \mathrm{f})$ & Subadulto $(\mathrm{m} / \mathrm{f})$ & Adulto $(\mathrm{m} / \mathrm{f})$ & Total $(\mathrm{m} / \mathrm{f})$ \\
\hline 1995 & $8(2 / 6)$ & $11(3 / 8)$ & $18(4 / 14)$ & $29(5 / 24)$ & $66(14 / 52)$ \\
1996 & $5(2 / 3)$ & $10(4 / 6)$ & $20(8 / 12)$ & $31(10 / 21)$ & $66(24 / 42)$ \\
1997 & $9(5 / 4)$ & $13(6 / 7)$ & $18(5 / 13)$ & $31(8 / 23)$ & $71(24 / 47)$ \\
1998 & $5(2 / 3)$ & $10(3 / 7)$ & $21(7 / 14)$ & $30(11 / 19)$ & $66(23 / 43)$ \\
1999 & $7(3 / 4)$ & $9(6 / 3)$ & $19(6 / 13)$ & $31(9 / 22)$ & $66(24 / 42)$ \\
2002 & $6(2 / 4)$ & $7(4 / 3)$ & $11(4 / 7)$ & $24(7 / 17)$ & $48(17 / 31)$ \\
2003 & $6(2 / 4)$ & $9(3 / 6)$ & $13(4 / 9)$ & $22(7 / 15)$ & $50(16 / 34)$ \\
Total & & & & & $433(142 / 291)$ \\
\hline
\end{tabular}

m/f: número de machos/número de fêmeas; infantil: 0-12 meses; juvenil: 13-36 meses; subadulto: 37-60 meses; adulto: $>60$ meses.

Durante o manejo médico anual realizado no Cecal-Fiocruz (Andrade et al., 2004), foram coletadas amostras fecais por suabe retal. Foram utilizados suabes em meio Cary Blair $^{1}$ para a conservação das amostras até o seu

\footnotetext{
${ }^{1}$ Plast Labor - Rio de Janeiro, Brasil.

${ }^{2}$ Difco - Kansas, EUA.

${ }^{3}$ Sigma - Rio de Janeiro, Brasil.

${ }^{4}$ Roche - São Paulo, Brasil.

${ }^{5}$ Upjohn - São Paulo, Brasil.
}

processamento. As fezes coletadas foram testadas de acordo com o protocolo de LauriaFilgueiras e Hofer (1998). As amostras foram semeadas em meio seletivo à base de ágar Columbia $^{2}$, acrescido com $05 \%$ de sangue desfibrinado de carneiro ou $0,4 \mathrm{~g} \%$ de carvão ativado, $05 \mathrm{~mL} \%$ de solução redutora FBP $(0,5 \mathrm{~mL} \%$ de sulfato ferroso, bissulfito de sódio e piruvato de sódio) e $0,5 \mathrm{~mL} \%$ solução de antibiótico (cefalotina ${ }^{3} 81 \mathrm{mg}$ ) + lactato de 
trimetoprim ${ }^{4} 25 \mathrm{mg}+$ vancomicina $^{3} 50 \mathrm{mg}+$ actidione $^{5} 10 \mathrm{mg}+$ colistina $^{3} 11 \mathrm{mg}+$ água destilada $25 \mathrm{~mL}$ ) e incubadas a $42^{\circ} \mathrm{C}$ por 48 horas em atmosfera de microaerofilia, gerada pelo método da passivação de cobre (Pinheiro et al., 1991) ou envelopes comercializados.

O diagnóstico presuntivo foi realizado após a incubação, com base na morfologia de colônia (transparentes com brilho d'água) e morfologia celular, por meio do método de Gram e de acordo com a descrição de Lauria-Filgueiras e Hofer (1998). Para o diagnóstico definitivo, utilizaram-se testes bioquímicos, tais como, hidrólise do hipurato de sódio e do acetato de indoxila, produção de Dnase e antibiograma (Lauria-Filgueiras, 2000).

Com a constatação da presença de Campylobacter spp. na população animal estudada e com o intuito de erradicar o agente na criação, alterações no manejo foram sendo realizadas no decorrer dos anos. No ano de 1998, houve uma modificação estrutural nas instalações onde estão alojados os macacos-de-cheiro, com a troca das placas de amianto do lanternim, localizado na entrada do prédio, por telhas de alumínio, a fim de prevenir infiltrações indesejáveis. Trocaram-se, também, as telas de proteção dos recintos, optando-se por um material de maior durabilidade (aço inoxidável). Em 2001, introduziu-se maravalha autoclavada nas gaiolas, evitando-se, assim, a lavagem diária do local para redução da umidade e consequente contaminação ambiental, além de menor frequência da circulação dos funcionários no interior das gaiolas, fato que contribui para minimizar o estresse dos animais.

Para a realização da coleta das amostras fecais, até o ano de 2000, era utilizado um coletor de metal de uso coletivo, higienizado com solução desinfetante entre um animal e o outro. A partir do ano de 2001, utilizaram-se suabes descartáveis estéreis e individuais. Outra medida sanitária adotada, a partir do ano de 2002, foi a lavagem dos alimentos vegetais, por meio de imersão em hipoclorito de sódio durante 15 minutos, antes do fornecimento aos animais.

\section{RESULTADOS E DISCUSSÃO}

De acordo com os testes realizados, as espécies isoladas, mais frequentes nos animais analisados, foram Campylobacter jejuni e C. coli. Outras espécies não tipificadas foram classificadas como Campylobacter spp. (Tab. 2).

Tabela 2. Frequência de Campylobacter jejuni, Campylobacter coli e Campylobacter spp. em macacosde-cheiro (Saimiri spp.) do criatório da Fundação Oswaldo Cruz no decorrer de sete anos

\begin{tabular}{ccccc}
\hline Ano & Amostras $^{1}$ & C. jejuni $(\%)$ & C. coli $(\%)$ & C. spp. $(\%)$ \\
\hline 1995 & $12 / 66$ & 7,6 & 6,1 & 4,5 \\
1996 & $16 / 66$ & 12,0 & 4,5 & 7,6 \\
1997 & $4 / 71$ & 2,8 & 2,8 & 1,4 \\
1998 & $5 / 66$ & 4,5 & 3,0 & 0 \\
1999 & $1 / 66$ & 1,5 & 0 & 0 \\
2002 & $1 / 48$ & 2,1 & 0 & 0 \\
2003 & $0 / 50$ & 0 & 0 & 0 \\
\hline
\end{tabular}

${ }^{ }$Amostras positivas/amostras analisadas.

Os resultados obtidos, para a população de macacos-de-cheiro, demonstraram que as taxas de positividade decresceram ao longo dos anos analisados (Fig. 1). Obteve-se o maior índice de positividade no ano de 1996 (24,24\%) e o menor índice em 2003 (0\%).

Fernández et al. (1994) observaram que, em indivíduos com diarreia, Campylobacter jejuni era mais frequente em relação a $C$. coli. Neste trabalho verificou-se, também em animais assintomáticos, maior frequência de $C$. jejuni. Scarcelli et al. (2005) detectaram a presença de $C$. jejuni em 5\% (18/366) de primatas analisados. A infecção por $C$. jejuni pode desencadear um quadro de paralisia neuromuscular (Scarcelli et al., 2005). Neste estudo, os animais portadores de Campylobacter spp. não apresentaram nenhum tipo de manifestação clínica.

Durante o período de análise, constatou-se ausência da infecção nos animais subadultos. Os maiores percentuais de positividade foram encontrados em animais jovens, durante os anos de 1995, 1997 e 2002. Já nos anos de 1996, 1998 e 1999, os maiores índices foram detectados nos animais adultos (Fig. 2). Estes resultados contradizem estudos anteriores, que afirmaram serem os animais mais jovens os mais afetados (Russel et al., 1987). 


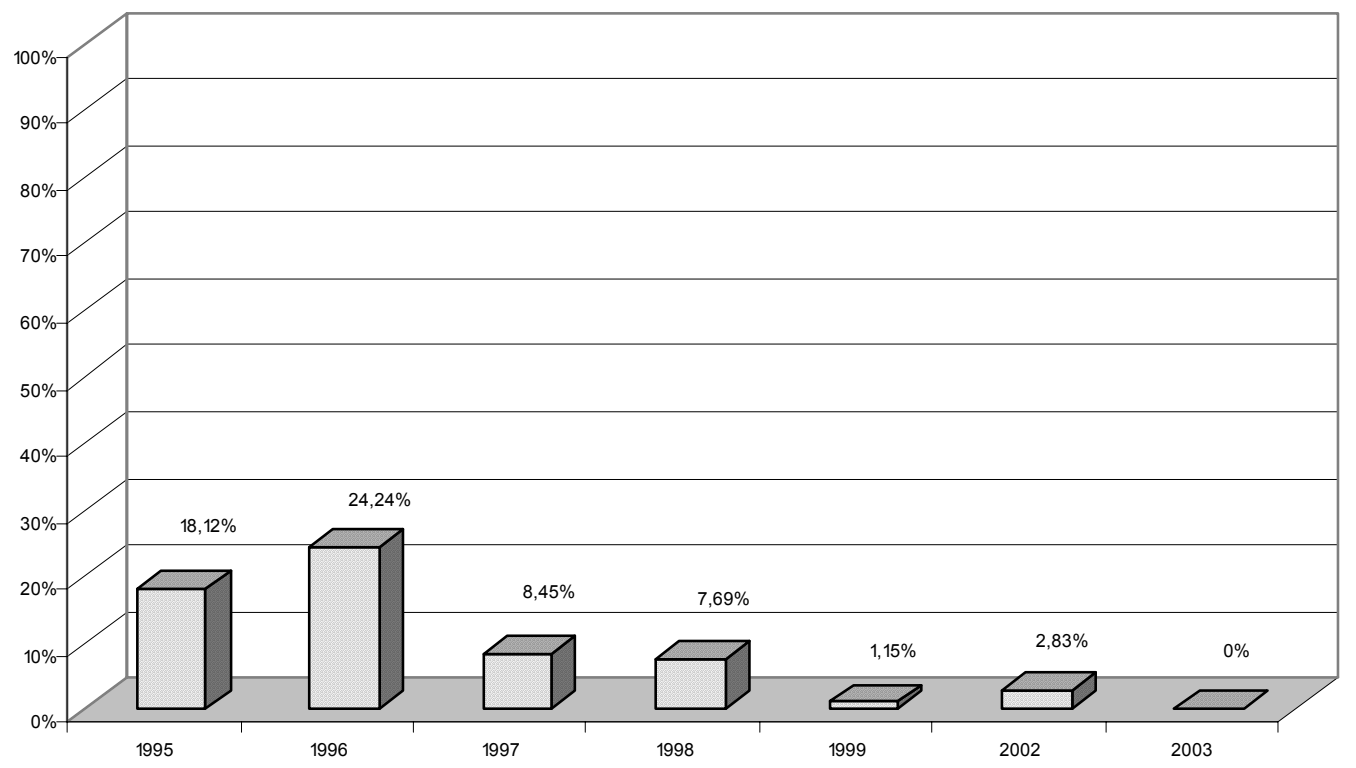

Figura 1. Frequência de isolamentos de Campylobacter spp. em macacos-de-cheiro (Saimiri spp.) do criatório da Fundação Oswaldo Cruz, de acordo com o ano.

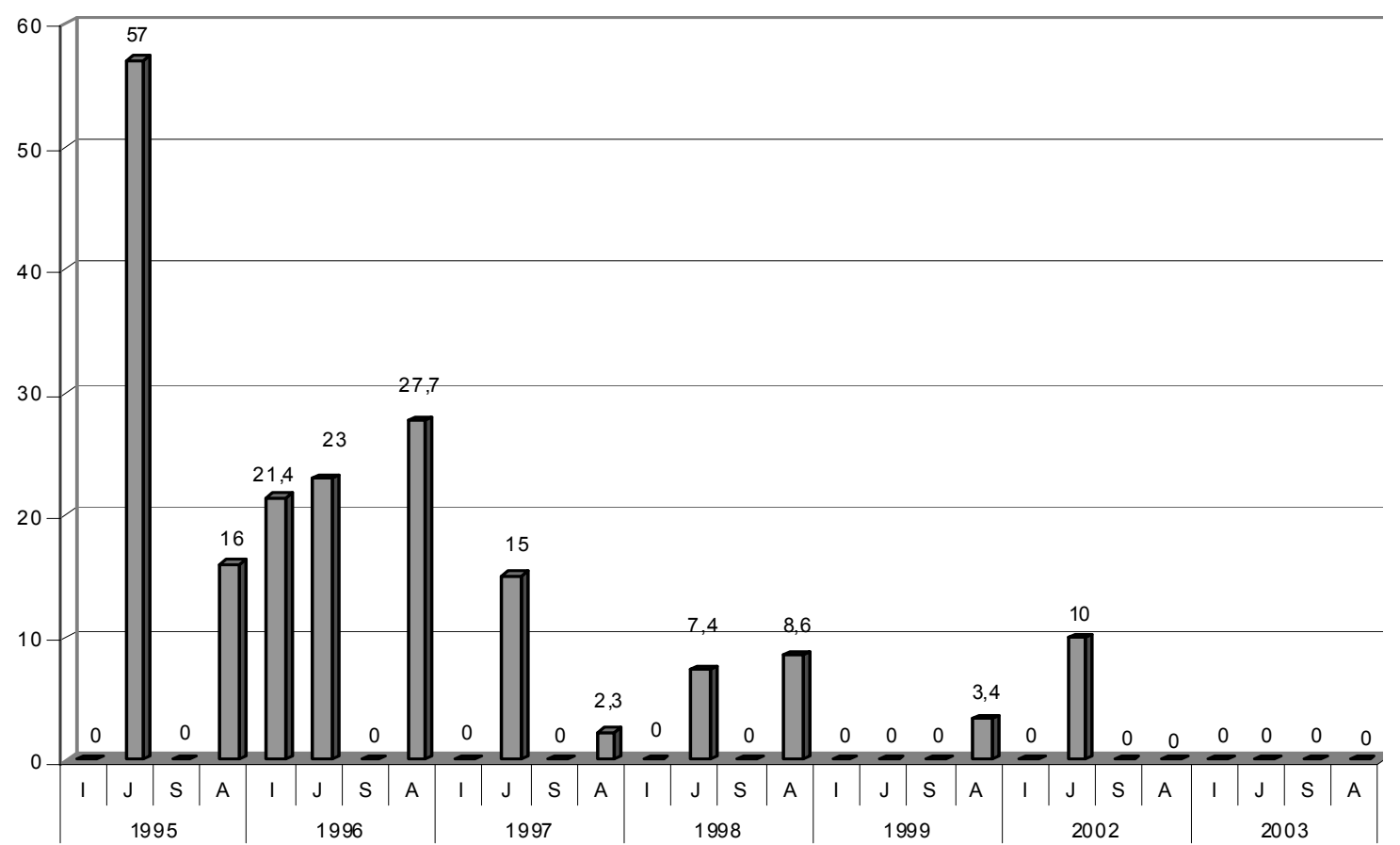

Figura 2. Frequência anual de isolamento de Campylobacter spp. em macacos-de-cheiro (Saimiri spp.) do criatório da Fundação Oswaldo Cruz, de acordo com as faixas etárias - I: infantil (0-12m); J: juvenil (13$36 \mathrm{~m})$; S: subadulto (37-60m), A: adulto ( $>60 \mathrm{~m})$. 
Os resultados deste trabalho sugerem que as alterações no manejo animal em relação à alimentação, à higienização e às instalações influenciaram na incidência de Campylobacter spp. na colônia de macacos-de-cheiro. As modificações estruturais dos recintos dos animais, por exemplo, auxiliaram na prevenção da entrada de roedores e pássaros nas gaiolas, já que, em geral, todos os animais podem constituir reservatórios assintomáticos ou mesmo veículos, representando sérios riscos à saúde (Tribe e Frank, 1980; Pei et al., 1991).

Segundo Fox (1982), animais de laboratório mantidos em confinamento geralmente são acometidos por estresse ambiental devido à superpopulação, às mudanças na dieta, à iluminação, à temperatura, à ventilação, à umidade e à alta circulação de indivíduos. Um ou uma combinação destes fatores pode induzir ao aparecimento de sinais clínicos da campilobacteriose, em animais que, até então, eram portadores assintomáticos. Dessa forma, a introdução da maravalha autoclavada nas gaiolas também pode ter sido uma medida eficaz.

Outra medida importante foi a substituição do coletor fecal não descartável pelos suabes, que, sem dúvida, constitui um método mais adequado para a coleta de amostras para análises, por prover resultado individual de maior confiabilidade e por evitar contaminações cruzadas (Fox, 1982).

O método mais efetivo para o controle de Campylobacter spp depende inteiramente da interrupção da sua transmissão entre os animais e os humanos, adotando-se medidas de higiene adequadas com a finalidade de eliminar o organismo infectante presente nos alimentos e na água (Perez-Perez e Blaser, 1996). De acordo com os exames semanais realizados nas amostras de água e alimentos vegetais lavados, enviadas ao laboratório para controle sanitário, a contaminação parasitológica nestes produtos foi eliminada totalmente.

Torna-se necessária uma melhor compreensão da patogenicidade da infecção causada por Campylobacter spp. em símios do gênero Saimiri spp. e da história natural da doença, para o desenvolvimento de métodos profiláticos e de controle.

\section{REFERÊNCIAS BIBLIOGRÁFICAS}

ANDRADE, M.C.R.; RIBEIRO, C.T.R.; SILVA, V.F. et al. Biologic data of Macaca mulatta, Macaca fascicularis, and Saimiri sciureus used for research at the Fiocruz Primate Center. Mem. Inst. Oswaldo Cruz, v.99, p.581-589, 2004.

BENNETT, B.T., ABEE, C.R., HENRICKSON, R. Nonhuman primates in biomedical research: diseases. San Diego: Academic, 1995, p.59-102.

DINIZ, L.S.M. Primatas em cativeiro, manejo e problemas veterinários: enfoque para primatas neotropicais. São Paulo: Icone, 1997.

DINIZ, L.S.M.; COSTA, E.O. Health problems of Callitthrix jacchus in captivity. Braz. J. Med. Biol. Res., v.28, p.61-64, 1995.

DUBOIS, R. Zoonoses transmissíveis por primatas no Brasil. A Hora Veterinária, v. 90, p.21-24, 1996.

EVANS, M.R.; RIBEIRO, C.D.; SALMON, R.L. Harzards of healthy living: bottled water and salad vegetables as risk factors for Campylobacter infection. Emerg. Infect. Dis., v.9, p.1219-1225, 2003.

FERNÁNDEZ, H.; KAHLER, K.; SALAZAR, R. et al. Prevalence of thermotolerant species of Campylobacter and their biotypes in children and domestic birds and dogs in southern Chile. Rev. Inst. Med. Trop. São Paulo, v.36, p.433-436, 1994.

FOX, J.G. Campylobacteriosis- A new disease in laboratory animals. Lab. Anim. Sci., v.32, p.625637, 1982.

GOZALO, A.; BLOCK, K.; MONTOYA, E. et al. A survey for Campylobacyter in feral and captive tamarins. In: EHARA, A.; KIMURA, T.; TAKENAKA et al. (Eds). Primatology today. Amsterdam: Elsevier, 1991. p.675-676.

GOZALO, A.; MONTOYA, E. Mortality causes of owl monkeys (Aotus nancymae and $A$. vociferans) in captivity. J. Med. Primatol., v.19, p.69-72, 1990.

GOZALO, A.; MOTOYA, E. Mortality causes of the moustached tamarin (Saguinus mystax) in captivity. J. Med. Primatol., v.21, p.35-38, 1992.

LAURIA-FILGUEIRAS, A.L.; HOFER, E. Diversity of campylobacter isolates from three 
activated sludge systems. Mem. Inst. Oswaldo Cruz, v.93, p.295-298, 1998.

LAURIA-FILGUEIRAS, A.L. Circulação de espécies termofilicas de Campylobacter em primatas não humanos mantidos em cativeiro, Rio de Janeiro. 2000. 125f. Tese (Doutorado) Instituto Oswaldo Cruz, Rio de Janeiro.

MONTALI, R.J.; BUSH, M. Diseases of the Calithrichidae. In: FOWLER, M.E.; MILLER, E. (Ed.). Zoo and wildlife medicine: current therapy. Philadelphia: W.B. Saunders, 1999. p.369-376.

PEI, Z.; ELLISON, R.T.; BLASER, M.J. Identification, purification, and characterization of major antigenic proteins of Campylobacter jejuni. J. Biol. Chem., v.266, p.16363-16369, 1991.

PEREZ-PEREZ, G.I.; BLASER, M.J. Campylobacter and Helicobacter. In: Medical microbiology. New York: Churchill Livingstone, 1996.

PINHEIRO, M.S.; BARRUCAND, L.; RICCIADI, J.D. et al. Evaluation of cefoxitin medium and the microaerophilic environment produced by a combination of iron, copper and sodium bicarbonate for culture of Campylobacter jejuni and Campylobacter coli. Rev. Microbiol., v.22, p.298-302, 1991.
RUSSEL, R.G.; KRUGNER, L.; TSAI, C-C et al. Prevalence of Campylobacter in infant, juvenile and adult laboratory primates. $L a b$. Anim. Sci., v.38, p.711-714, 1988.

RUSSEL, R.G.; ROSENKRANZ, S.L.; LEE, L.A. et al. Epidemiology and etiology of diarrhea in colony-born Macaca nemestrina. Lab. Anim. Sci., v.37, p.309-316, 1987.

SÁ, L.R.M.; SCARCELLI, L.; DUARTE, M.I.S. Prevalência de Campylobacter jejuni em população de calitriquídeos mantidos em cativeiro na região de Jundiaí, SP. Arq. Inst. Biol. São Paulo, v.68, supl., p.89. (Resumo).

SCARCELLI, E.; PIATTI, R.; HARAKAVA, R. et al. Molecular subtyping of Campylobacter jejuni subsp jejuni strains isolated from different animal species in state of São Paulo, SP, Brazil. Braz. J. Microbiol., v.34, p.378-382, 2005.

TRIBE, G.W.; FRANK, A. Campylobacter in monkeys. Vet. Rec., v.106, p.365-366, 1980. 